\title{
41 ADVANCE DIRECTIVE (LIVING WILL) COMPLETION AND INTENTION OF COMPLETION RATES IN ALBERTA
}

10.1136/bmjspcare-2011-000053.41

D Wilson', J Cohen², S Aliyar1 ' University of Alberta, Edmonton, Canada; ${ }^{2}$ Brussels End-of-life Research Group, Belgium

Canadian provinces have had laws for 10 years to guide developing and use of advance directives (living wills). Although laws reflect public preferences, living will completion rates have been identified as low. A public survey in Alberta Canada was done for information on current living will completion or intention rates. The University of Alberta's Population Research Laboratory was asked to add questions to their annual telephone survey. This survey is carefully conducted for correct population proportions and results highly (95\%) representative of all persons aged $18+$. In May-July 2010, 1203 were surveyed and 43.6\% reported having a current living will and $42.1 \%$ reported thinking about or planning one; $14.3 \%$ said they did not need or want one. Significant differences across population sub-groups were found, with higher completion rates among persons who had been involved in a decision to stop or not start life support, had cared for a dying person, had a close family member or friend who died, had been involved in a decision to put a pet or another animal down, described themselves 
as religious, were over age 64 and were married or divorced/ widowed. Albertans have a relatively high rate of completion and intention of completion, with factors having lead to this state of interest. With the number of deaths expected to double in the future, and with public experience of death and dying increasing, living will completion rates could increase. This information should be taken into consideration for future developments in advanced care planning and end-of-life care. 